\title{
EREBEA
}

Revista de Humanidades y Ciencias Sociales

NúM. 9 (2019), pp. 81-104

ISSN: 0214-0691

http://dx.doi.org/10.33776/erebea.v9i0.3786

\section{Anima olea. El arte EN LA INTERPRETACión DEL PAISAJE DEL OLIVAR COMO PATRIMONIO NATURAL Y CULTURAL}

\author{
Carmen Andreu Lara \\ Universidad de Sevilla
}

RESUMEN

El olivar es el cultivo mediterráneo por excelencia, donde destaca tanto por su extensión como por su importancia milenaria. La cultura que se le asocia hunde sus raíces en los primeros procesos de domesticación agraria y ha tenido un papel fundamental en la ecología, la economía, la historia y la belleza del Mediterráneo y sus paisajes.

Este artículo tiene como objetivo fundamental abordar desde una perspectiva artística, interdisciplinar y transdiciplinar los valores del paisaje del olivar andaluz, analizando algunas de las formas objetivas que ha adoptado en distintas áreas del territorio y profundizando en las percepciones y las emociones que estas suscitan. Partimos del estudio interdisciplinar de los valores de los paisajes de olivar para destacar su riqueza antropológica y estética, como patrimonio natural y cultural, sin olvidar algunos de los principales problemas ambientales que está suponiendo para estos las exigencias crecientes del mercado que lleva en numerosas ocasiones a la adopción de insumos y manejos insostenibles en el tratamiento del olivo en menoscabo de la riqueza de estos paisajes. Damos un paso metodológico más desarrollando trabajos de carácter transdisciplinar que abordan el paisaje del olivar creando relatos más allá del contexto disciplinar de los participantes.

Palabras Clave

Paisaje, arte, olivar mediterráneo, hermenéutica

Fecha de recepción: 19 de noviembre de 2019 Fecha de aceptación: 5 de diciembre de 2019

\section{ABSTRACT}

The olive grove is the pre-eminent crop in the Mediterranean Sea, where it stands out due the extension of the crops and its millenary importance. The olive culture is rooted in the very first processes of agrarian domestication, and it played a major role in the ecology, economy, history and beauty of the Mediterranean sea and its landscapes.

The main goal of this article is to address the value of the Andalusian, olive-growing landscapes from an artistic, interdisciplinar and transactional perspective by analysing some of the objective shapes that they have adopted in various areas of the territory and delving into the perceptions and emotions that they arouses. We start with the interdisciplinar study of the values of the olive-growing landscapes to emphasise their anthropologic and aesthetic wealth as a natural and cultural heritage, acknowledging some of the major environmental problems that are taking place, consequence of the increase in market demand that leads to the extraction of supplies and the use of unsustainable control treatments at the expense of the wealth of these landscapes. We go further on the methodology by developing interdisciplinary works that would address the olive-growing landscapes, creating stories beyond the disciplinar context of the participants.

KEYwORDS
Landscape, art, Mediterranean olive
grove, hermeneutics





\section{INTRODUCCIÓN}

El olivar es el cultivo mediterráneo por excelencia, donde destaca tanto por su extensión como por su importancia milenaria. La cultura que lleva asociada hunde sus raíces en los primeros procesos de domesticación agraria y ha tenido un papel fundamental en la ecología, la economía, la historia y la belleza del Mediterráneo y sus paisajes.

El 27 de enero de 2017, la UNESCO incluyó los paisajes del olivar de Andalucía en la lista indicativa de Patrimonio Mundial de España. La candidatura de tales paisajes andaluces, que comprende a las provincias de Cádiz, Jaén, Granada, Córdoba, Sevilla y Málaga se encuentra ahora en fase de inventario del patrimonio cultural.

Si consideramos la declaración de Patrimonio Mundial, no como un fin en sí mismo, sino como un compromiso para la preservación de los valores reconocidos, para que estos reviertan en beneficio de las comunidades locales y de la sociedad en general, se hace necesario establecer vías de reflexión y comunicación sobre estos valores que redunden en el afianzamiento del vínculo social con estos paisajes y que promuevan su preservación y autenticidad y evite banalizaciones y deterioros.

La serie artística Anima olea es resultado de la investigación desarrollada dentro del proyecto "Los paisajes culturales de la Lista de Patrimonio Mundial. Claves para su identificación y criterios para la gestión de dehesas, montados ibéricos y olivares mediterráneos" con REFERENCIA: CSO2015-65787-C66-P, financiado por el Ministerio de Economía y Competitividad, periodo 20162020 .

El proyecto ha tenido como objetivo fundamental abordar desde una mirada compartida e interdisciplinar las bases espaciales, territoriales y paisajísticas del olivar andaluz, poniendo en evidencia sus caracteres excepcionales de adaptación ecológica, su papel histórico fundamental en la economía y la sociedad regional y su importancia secular como paisaje fundante de Andalucía.

Desde este punto de partida, hemos realizado una lectura directa, hermenéutica y transdisciplinar de los paisajes del olivar existentes hoy en Andalucía, analizando las formas objetivas presentes actualmente en distintas áreas del territorio, fundamentalmente por proximidad geográfica Sevilla, Huelva, Cádiz y Jaén, para profundizar en las percepciones y las emociones que suscitan. 
Todo ello nos ha llevado a la realización de un proyecto artístico, Anima olea, que se propone trasladar de manera didáctica algunos de los resultados de esta investigación y afronta el reto de establecer un espacio de reflexión y diálogo sobre algunos de los valores fundamentales de los paisajes de olivar, su riqueza antropológica y estética, como patrimonio natural y cultural, sin olvidar la problemática ambiental y social que está suponiendo para estos las exigencias crecientes del mercado que lleva en numerosas ocasiones a la adopción de prácticas y manejos en el tratamiento del olivo muy distanciados del olivar tradicional que revierten de manera directa en menoscabo de la riqueza de estos paisajes.

\section{Fundamentos teÓRICOS Y METODOLOGÍA}

Son muchos los autores que atendiendo a la complejidad del concepto de Paisaje hoy, han llamado la atención sobre la necesidad de evitar tanto los objetivismos cientificistas como los subjetivismos idealistas para aprehenderlo (Besse, 2000; Berque, 2009; Martínez de Pisón, 2012; Ojeda-Rivera, 2013). Parece claro hoy que la interpretación del paisaje y de otras realidades complejas -en las que se mezclan un sustrato físico y objetivo con emociones y significaciones subjetivasrequiere trascender los límites de las disciplinas para llegar a deducciones más comprensivas y ajustadas a su complejidad.

En esta línea, el arte, su poder simbólico y metafórico, constituye en sí mismo un medio eficaz para comprender la complejidad del paisaje y poder transmitirla interpretativamente (López Gómez, 2011; Caballero, 2012; Ojeda-Rivera, 2013).

Anima olea toma como punto de partida los antecedentes de experiencias artísticas encaminadas a sensibilizar respecto de la acción humana sobre el medio natural (Andreu, 2013; Bilbao, 2015; Ojeda, 2015 y otros), con el fin de suscitar una reflexión sobre los valores patrimoniales de los paisajes del olivar andaluz y su problemática ambiental y social.

Por otra parte, aborda la lectura interdisciplinar de los paisajes del olivar trabajando desde la historia, la geografía y el arte. Los resultados de este trabajo se han publicado en el Atlas de los paisajes patrimoniales de España y en el artículo Razones y recelos de un reconocimiento patrimonial: los paisajes del olivar andaluz publicado en el Boletín de la Asociación de Geógrafos Españoles en 2018.

Más allá de estas lecturas, hemos desarrollado el método transdisciplinar y hermenéutico de lectura paisajística, propuesto por el geógrafo Juan F. OjedaRivera $(2013,2015)$, compartiendo su aplicación al olivar andaluz con el mismo investigador y con el historiador Juan Infante-Amate. Las categorías básicas de la gramática hermenéutica (límites, componentes principales, atributos y núcleo de sentido) han ido produciendo interesantes emergencias en los intersticios de nuestras respectivas miradas disciplinares, a las que se fueron ańadiendo otros registros literarios, sociológicos y antropológicos constituyendo tal convergencia la base de la obra artística que se presenta en este artículo. 

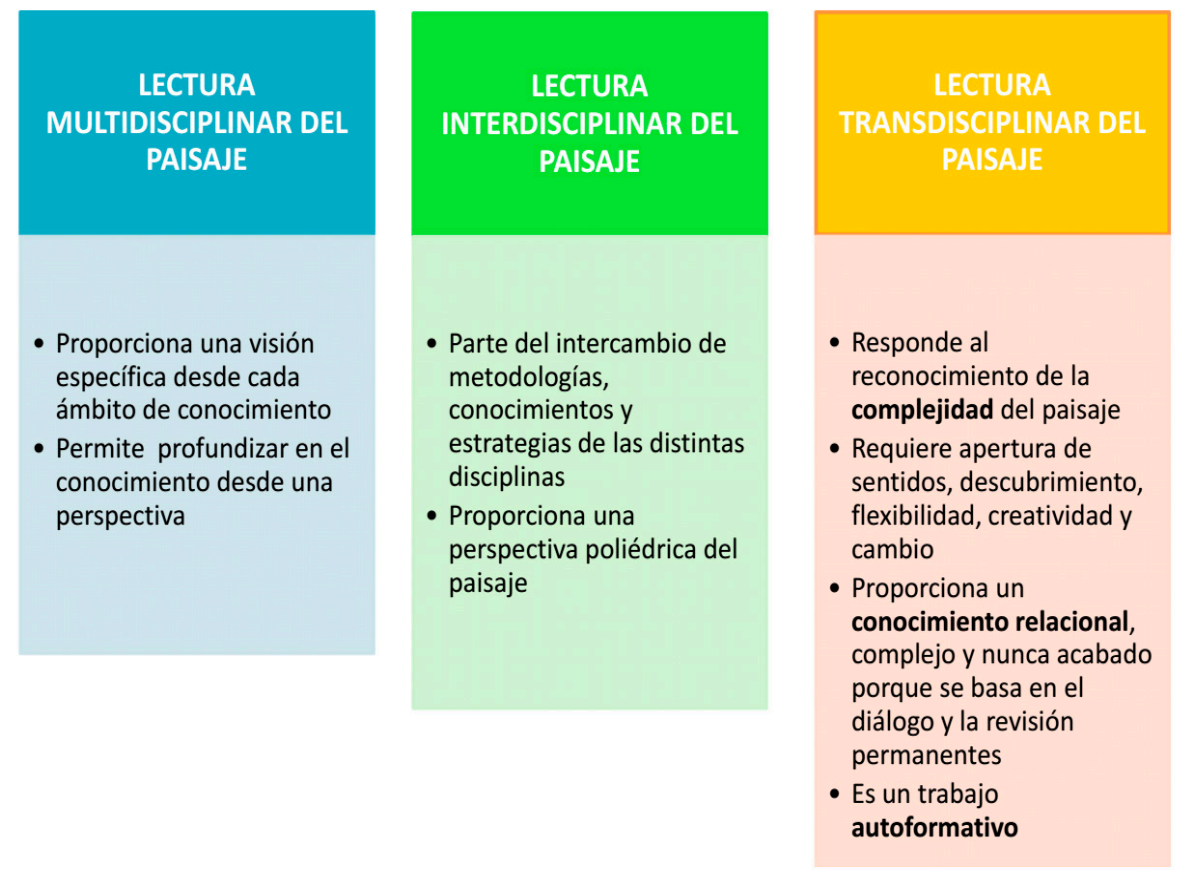

Fig. 1. Esquema comparativo del abordaje multidisciplinar, interdisciplinar y transdisciplinar. Elaboración propia

Para el trabajo transdisciplinar, en una primera fase, hemos partido del análisis del proceso histórico de expansión del olivar en Andalucía y su distribución geográfica (Guzman, 2005; Infante-Amate, 2014; Gómez Calero, 2009; Sánchez Ruiz, 2018) lo que nos ha permitido iniciar nuestra interpretación considerando las claves geohistóricas del olivar andaluz y sus diferentes morfologías, relacionándolas con sus manejos y sistemas de explotación que han ido cambiando a lo largo de la historia al ritmo de las transformaciones tecnológicas.

Posteriormente hemos desarrollado una fase del trabajo compartido de carácter abierto y sorpresivo que encuentra un cimiento epistemológico claro en el modelo rizoma de Guattari y Deleuze (en el que cualquier predicado afirmado de un elemento puede incidir en la concepción de otros elementos de la estructura, sin importar su posición recíproca). En esta fase, ha sido fundamental el intercambio de datos, percepciones e intuiciones de todo el equipo investigador. Algunos de los resultados más significativos de esta fase de la investigación han sido publicados en la revista BAGE (Ojeda-Rivera, Andreu-Lara, Infante-Amate, 2018)

Por último, hemos llevado a cabo la ejecución de la obra artística que se analiza en este artículo y que viene a constituir la materialización hermenéutica libre y abierta del proceso de trabajo compartido con los investigadores del equipo. 


\section{Resultados}

Presentamos a continuación los trabajos artísticos más significativos en torno al olivar andaluz y sus paisajes desarrollados en este proyecto.

\subsection{APROXIMACIÓN INTERDISCIPLINAR AL OLIVAR ANDALUZ}

La serie de estudios ha sido realizada IN SITU, en distintos enclaves del olivar andaluz buscando una caracterización tipológica de sus paisajes. El trabajo de campo es la base de estos estudios y apuntes porque la percepción plurisensorial en el territorio es indispensable para la compresión del olivar en su complejidad. La búsqueda abierta por los campos de la geografía andaluza, la inmersión en el territorio, la percepción atenta, constituyen el principio clave de estos trabajos. Sentir el calor del campo, escuchar el sonido de la chicharra y el vuelo del zorzal, oler la tierra y el sabor amargo de la aceituna constituyen estrategias básicas para la aproximación desinteresada y abierta del pintor al paisaje del olivar en un proceso
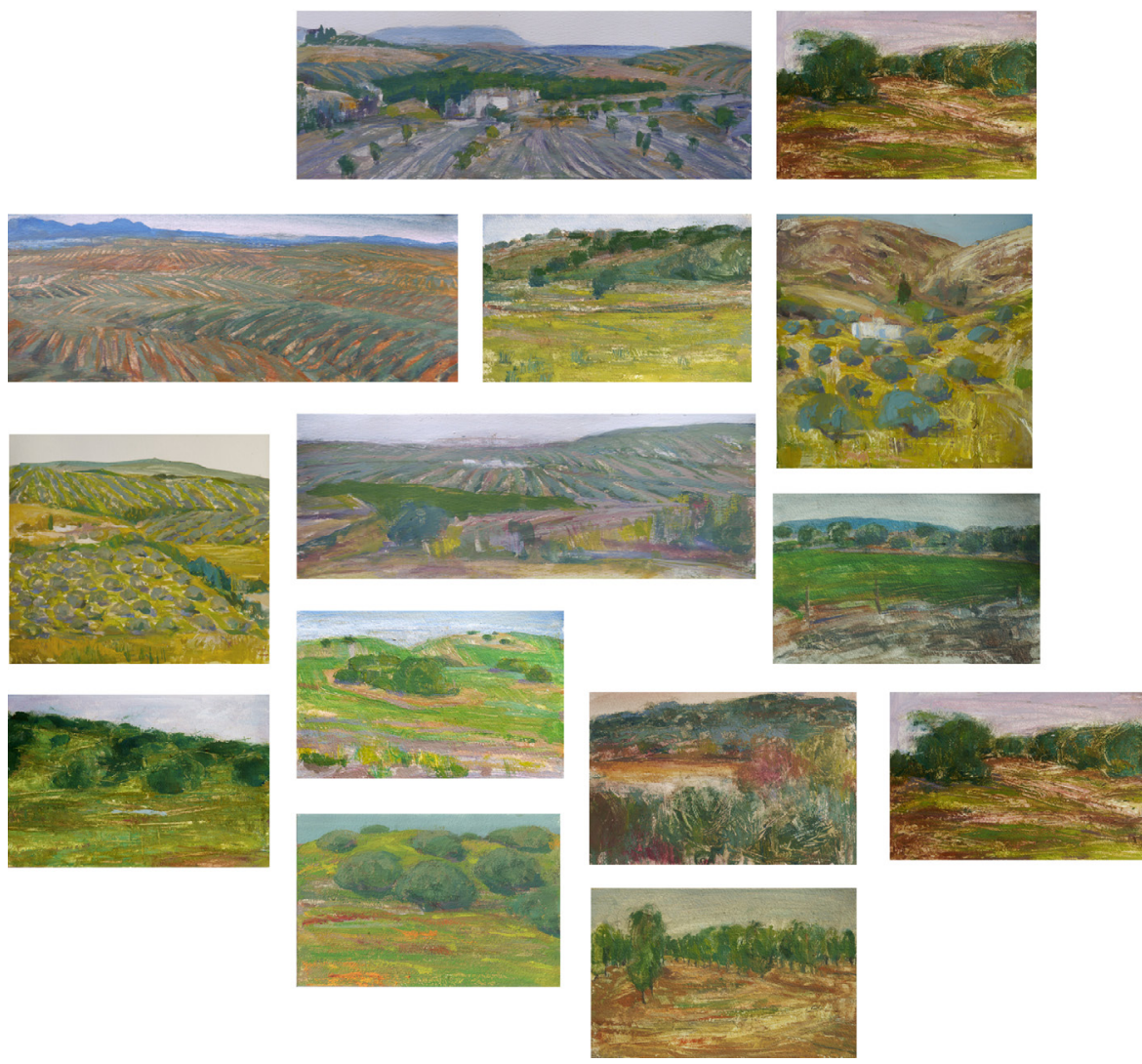

Fig. 2 Aproximación interdisciplinar al olivar andaluz, 2019.

Apuntes de temple de huevo sobre papel. Medidas variables 
de "redescubrimiento". Aunque no se ha realizado de una manera sistemática aplicando categorizaciones preestablecidas, a través de la interpretación pictórica se destacan diferentes formas del olivar andaluz, desde las dehesas de acebuches tan importantes en el contexto de Cádiz (Dehesas del Pilón, la Zorrilla y la Janda) y Sevilla (Dehesa de Abajo), hasta el olivar de montaña (sierra de Huelva), de ruedos (Cortelazor, Espera y Aznalcázar, entre otros), de cortijos (Alhama de Granada), hasta los olivares en espaldera que comienzan a instalarse en distintas comarcas como Osuna y Los palacios (Sevilla).

Esta primera aproximación disciplinar será la base para establecer un diálogo interdisciplinar posterior.

\subsection{DIVERSITAS OLEA, 2019}

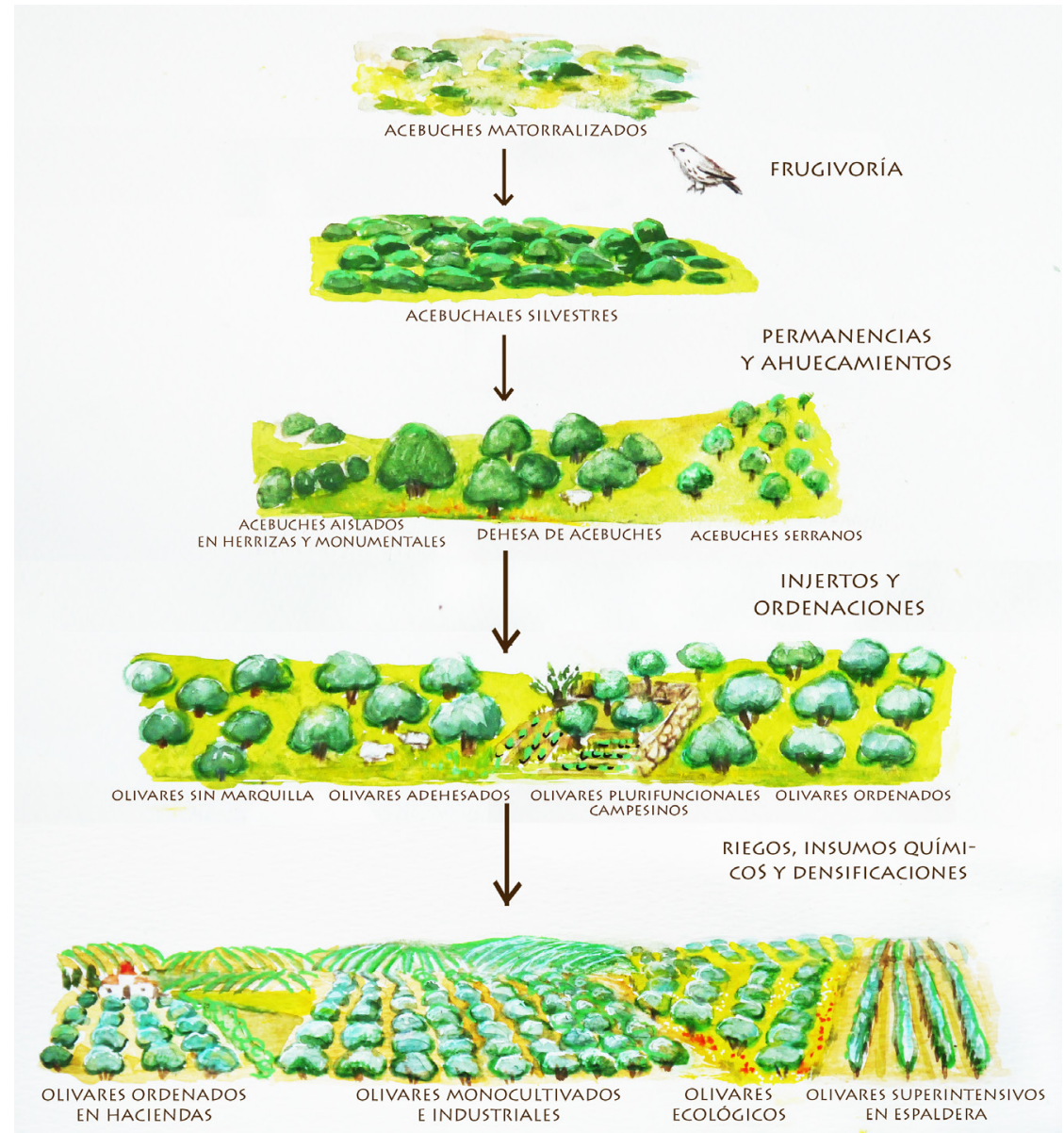

Fig. 3. Genealogía del olivar. Fuente: C. Andreu; J. Infante-Amate; J. Ojeda. Resultado del Diálogo transdisciplinar. 2016 
A partir de los apuntes y estudios realizados del natural y el diálogo abierto con el geógrafo Juan F. Ojeda Rivera y el historiador Juan Infante Amate, se han categorizado las distintas adaptaciones históricas y geográficas del olivar como sabias y elaboradas respuestas a las necesidades de su cultivo, a través de la elaboración del precedente árbol genealógico del olivar, que consideramos una síntesis del trabajo interdisciplinar, donde se presenta de manera esquemática y sencilla el resultado de lecturas, estudios, apreciaciones y convergencias. La imagen pretende servir como enlace hermenéutico con una población no especializada que pueda comprender con facilidad los resultados de los trabajos realizados hasta ese momento.

Teniendo como referencia este esquema, se ha desarrollado una interpretación plástica en un políptico que pretende destacar la diversificación dinámica del olivar y sus paisajes de una manera sintética y esquemática.

La obra parte del matorral mediterráneo, diverso y rastrero, donde destacan las manchas oscuras del acebuche matorralizado que emerge en diversos puntos (fig. 4).

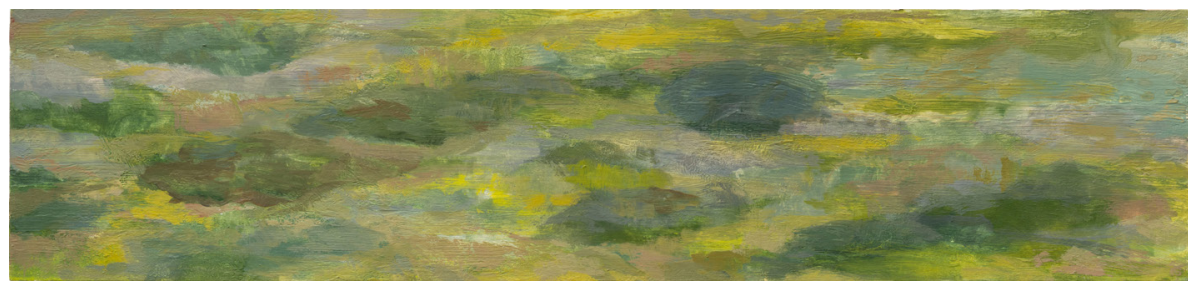

Fig. 4 Matorral mediterráneo.

Temple de huevo sobre tabla. $75 \times 25 \mathrm{~cm}$

Es característica de las partes costeras de la vegetación mediterránea la maquia o comunidad preforestal, vestigio del antiguo bosque, donde dominan especies como el acebuche, el algarrobo, la encina, las pistacias, etc. (González Bernáldez, 1992: 136)
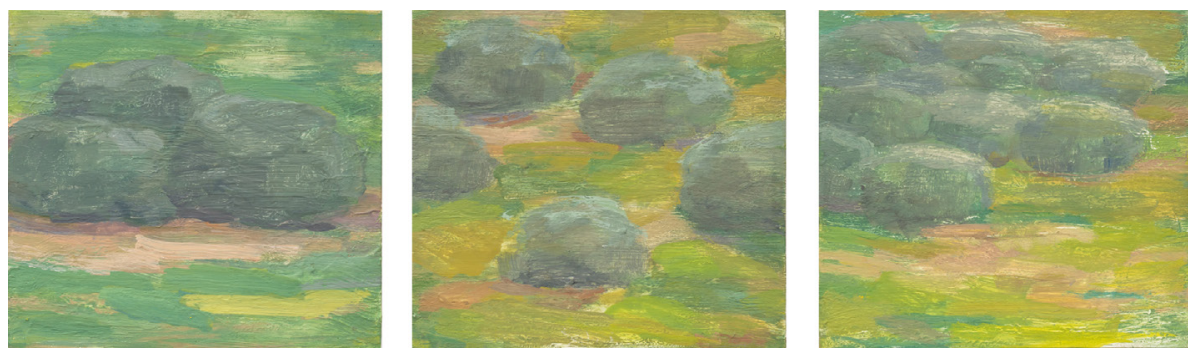

Fig. 5 Modelos de acebuches: en herrizas, dehesas y dispersos.

Temple de huevo sobre tabla. 25 x $25 \mathrm{~cm} \mathrm{c/u}$

En una segunda línea (fig. 5) se presentan tres piezas que representan la expansión del acebuche con su progresiva domesticación, mediante injertos y ordenaciones, que han permitido la conformación de acebuchales con distinto carácter, como 
la dehesa de acebuches, los acebuchales de montaña y los acebuches aislados y monumentales representado por las características herrizas de nuestros campos.
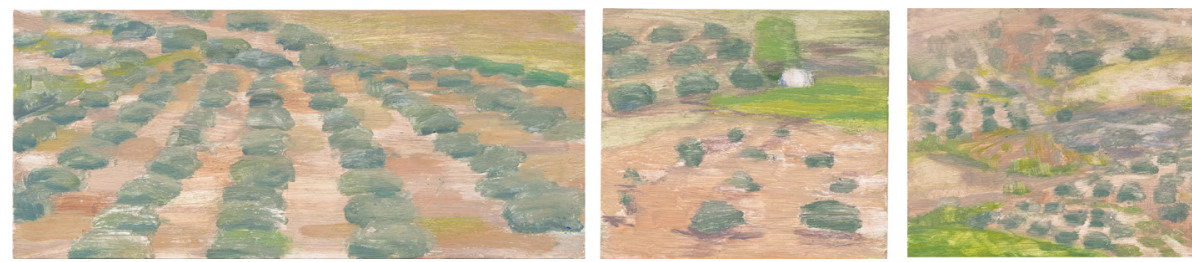

Fig. 6 Modelos de olivares semiintesivos, integrados en ruedos y olivar de montańa. Temple de huevo sobre tabla. $51 \times 25 \mathrm{~cm}, 25 \times 25 \mathrm{~cm}$ y $25 \times 25 \mathrm{~cm}$

En una tercera línea (fig. 6) se presenta la diversificación y domesticación del acebuche en nuestros olivares más genuinos con tres piezas que simbolizan el olivar poco capitalizado y con un marcado carácter multifuncional con un aprovechamiento más próximo a manejos agroforestales, los pequeños olivares integrados en los ruedos y los olivares propios de cultivo intensivo y ordenado en hileras.
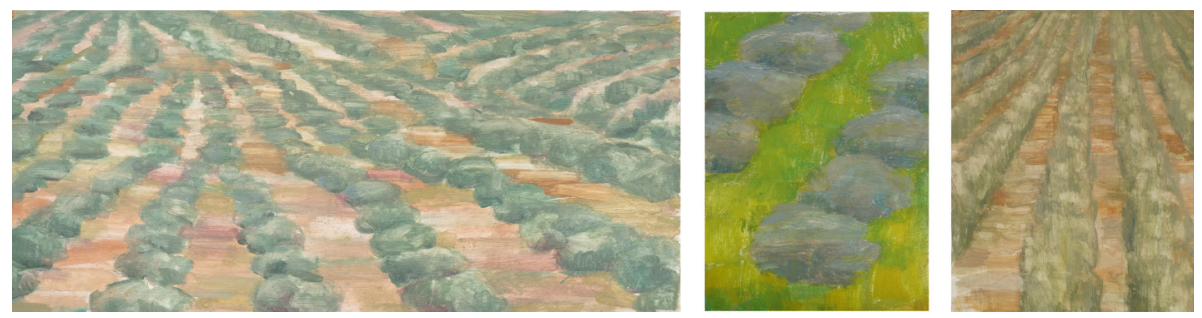

Fig. 7 Modelo de olivar intensivo, ecológico y en espaldera.

Temple de huevo sobre tabla. $75 \times 40 \mathrm{~cm} 25$ x $40 \mathrm{~cm}$ y $25 \times 40 \mathrm{~cm}$

Por último (fig. 7), a los olivares tradicionales se añaden los paisajes del olivar superintensivos propiciados en las últimas décadas por la intensificación de los riegos y los insumos químicos. La siguiente pieza simboliza las pequeñas iniciativas de olivares ecológicos, con un paisaje cromático y sonoro que recupera manejos tradicionales - proliferación de cubiertas, integración con ganado...Por último se identifica la cada vez más masiva proliferación de olivares en espaldera que redundan en la tecnificación, la reducción evidente de la riqueza biológica asociada al olivo y la reducción de costes de mano de obra. La última pieza delata otros fenómenos reseñables en los cambios del cultivo como la creciente utilización de maquinaria agrícola o tratamientos químicos en el manejo de la cubierta vegetal que hacen que buena parte de los olivares de la región apliquen manejos muy intensivos que terminan por eliminar completamente la vegetación, desnudando totalmente sus parcelas de tierra. 


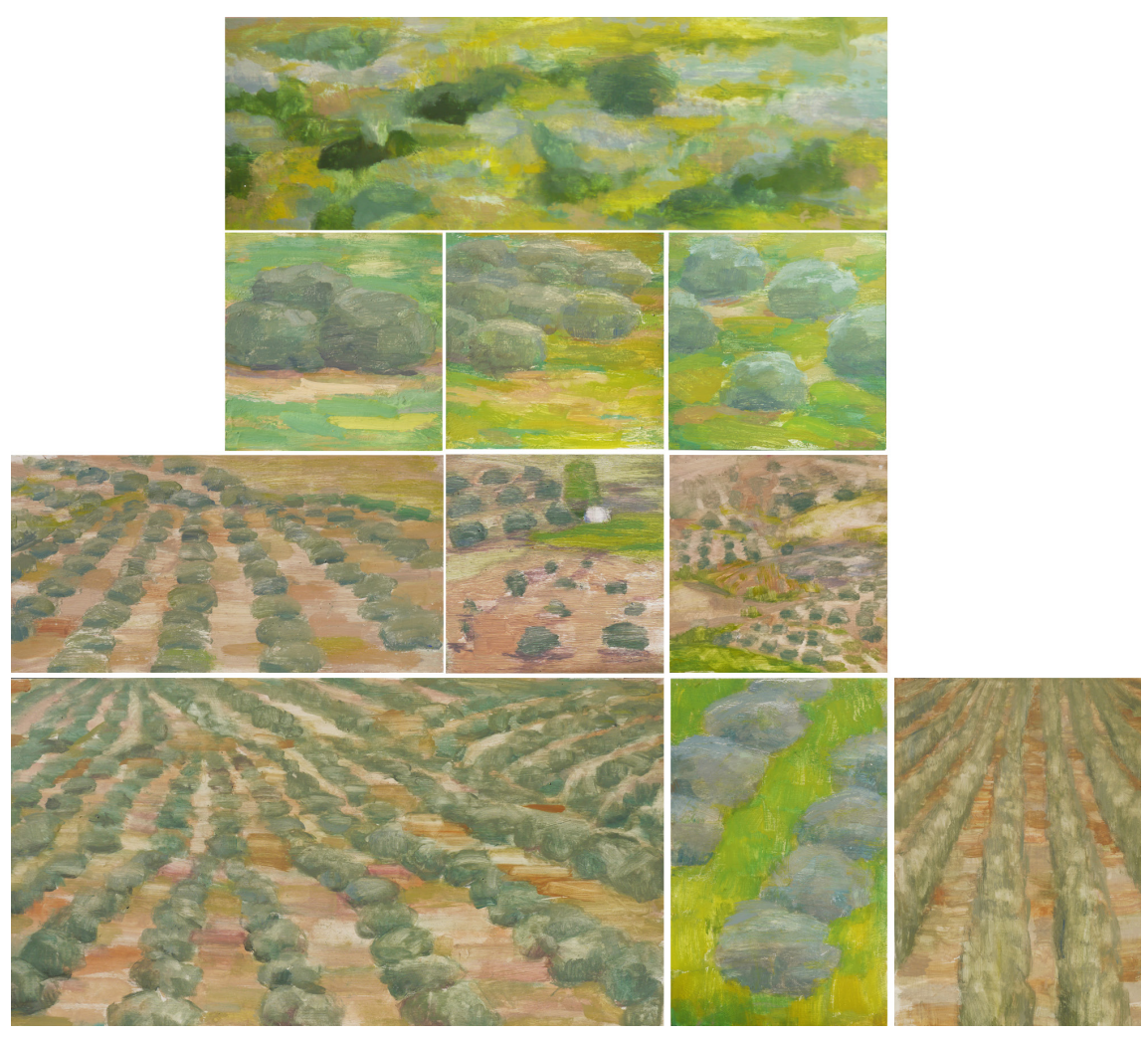

Fig. 8 Diversitas olea, 2019.

Temple de huevo sobre tabla. 118 x $132 \mathrm{~cm}$ dimensión global (separación calles $1 \mathrm{~cm}$ )

En su conjunto (fig. 8), constituyen una descripción simbólica de las distintas funcionalidades y adaptaciones históricas y geográficas de manejos y paisajes del olivar que todavía hoy podemos encontrar y que nos hablan de la complejidad del árbol y de sabias y elaboradas respuestas a necesidades en este territorio mediterráneo y que cuestiona su futuro.

\subsection{ANIMA OLEA}

Los procesos de intensificación del cultivo del olivo permiten adquirir con facilidad madera de olivos centenarios que están siendo sustituidos por garrotes nuevos alineados a corta distancia. La serie Anima olea que da título a este artículo se inicia con el paseo por olivares en proceso de cambio. En este paseo se singularizan algunos de los troncos encontrados que están siendo en la mayoría de las ocasiones utilizados como leña. El proceso de creación parte de la selección de las piezas, el diálogo con cada una de sus formas, con cada veta, con cada cicatriz. Los troncos son cortados y lijados para potenciar la expresividad de sus vetas y formas. 

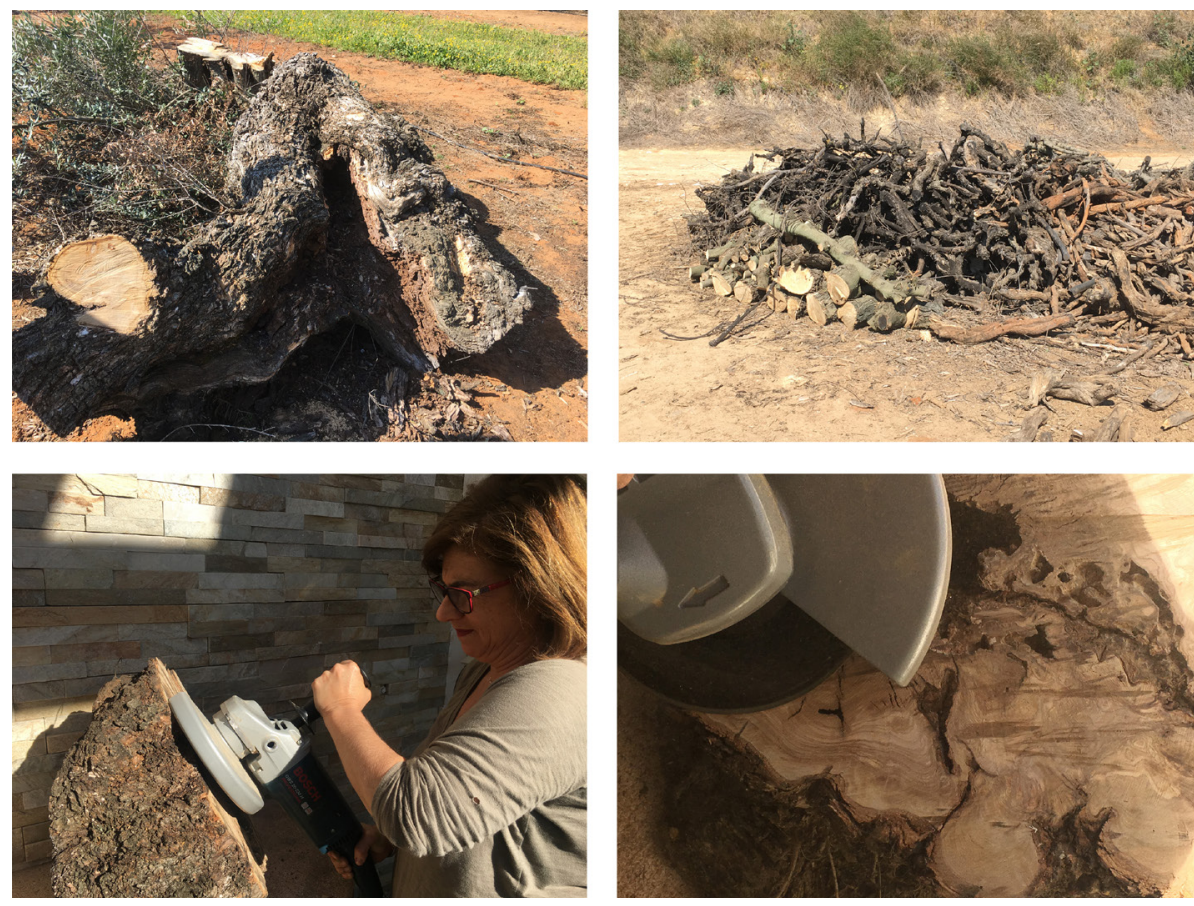

Fig.9 Proceso de selección, lijado y tratamiento de los troncos de olivo para la elaboración de las piezas.

Caminar por los olivares andaluces evoca sin dificultad algunos de los poemas que todos hemos recitado de niños: campo, campo, campo, entre los olivos, los cortijos blancos. Se han tomado prestado algunos de los versos más significativos de nuestra literatura que hacen referencia al olivo y a sus paisajes y se han transferido siguiendo los ritmos de las vetas que en muchas ocasiones sugieren paisajes. Cada pieza invita a detenerse, leer la veta de la madera, encontrar signos de la vida del árbol, rastrear el curso de la historia silenciosa del olivo viejo, identificarnos con su poesía, recuperar la memoria de la tierra, descubrir cicatrices, imaginar las heridas. 


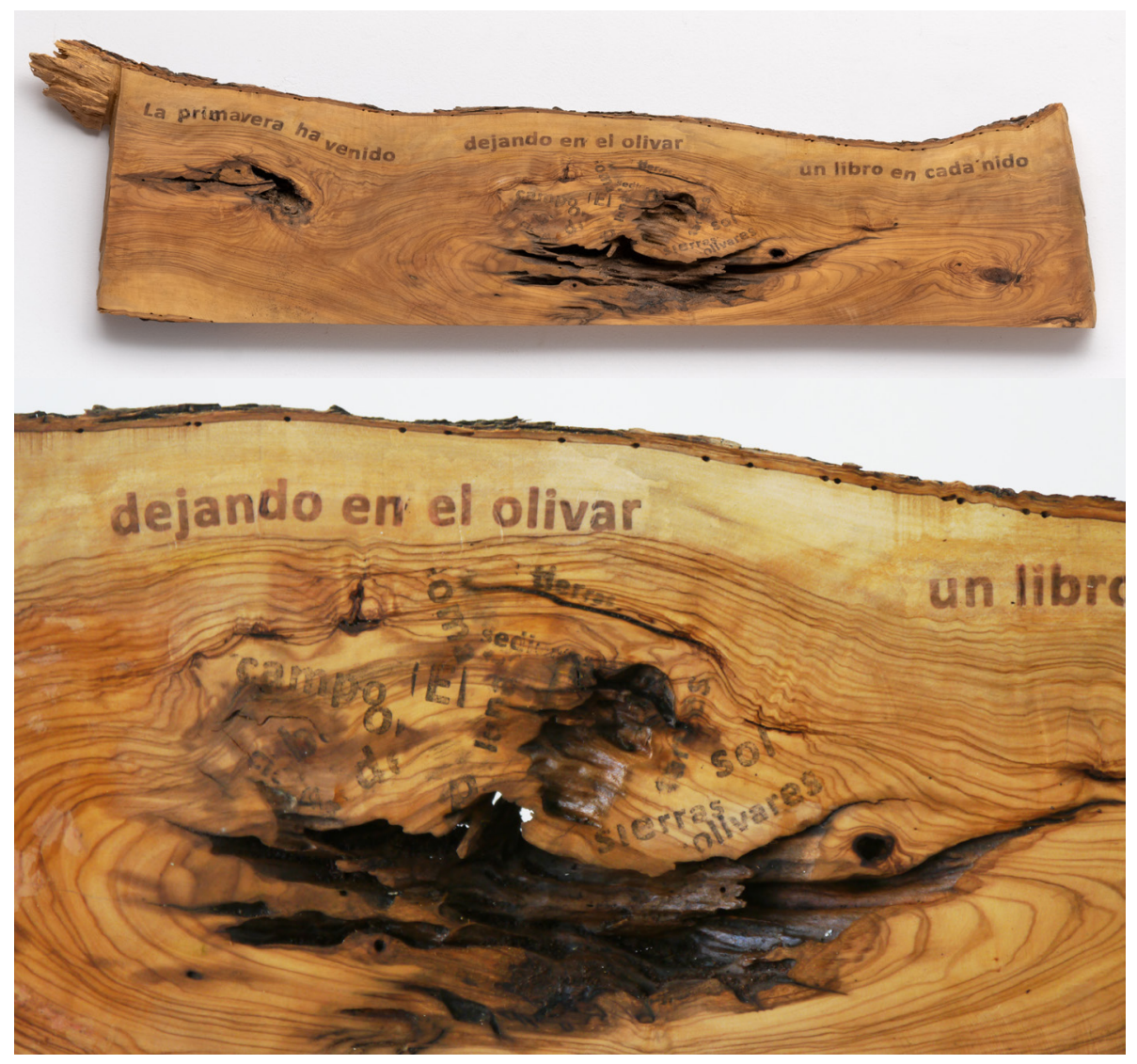

Fig. 10 Anima olea (Rafael Alberti), 2019. Pieza y detalle.

Transferencia sobre madera de olivo viejo. $22 \times 71 \times 3 \mathrm{~cm}$

\section{La primavera ha venido \\ dejando en el olivar \\ un libro en cada nido. \\ (Rafael Alberti)}




\subsection{B ANIma Olea en Federico García LORCA}
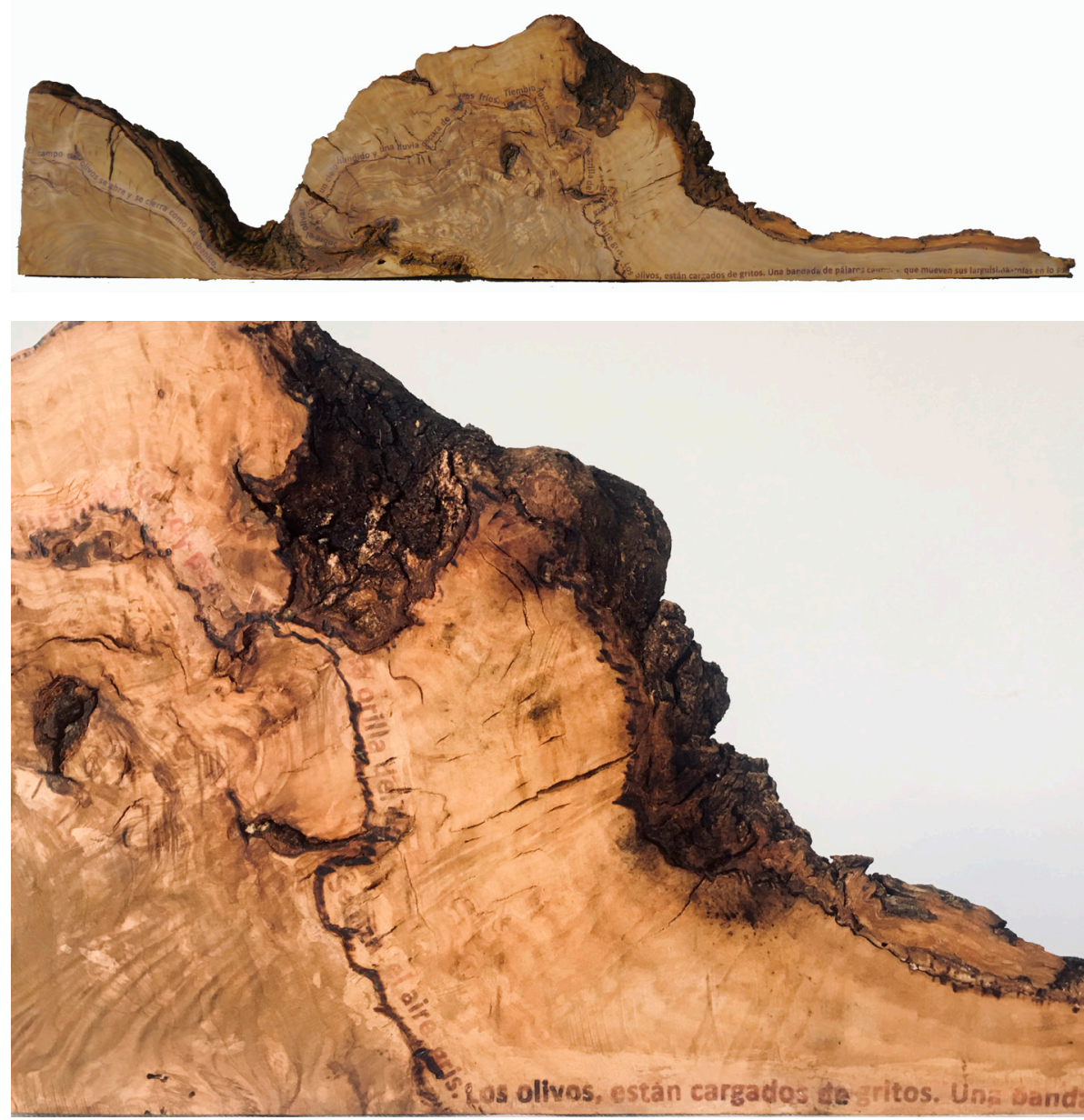

Fig. 11 Anima olea (García Lorca), 2019. Pieza y detalle.

Transferencia sobre madera de olivo viejo. 26 x 101 x $10 \mathrm{~cm}$
El campo
de olivos
se abre y se cierra
como un abanico.
Sobre el olivar
hay un cielo hundido
y una lluvia oscura
de luceros frios. 
Tiembla junco y penumbra

a la orilla del río.

Se riza el aire gris.

Los olivos,

están cargados

de gritos.

Una bandada

de pájaros cautivos,

que mueven sus larguisimas

colas en lo sombrio.

(Federico García Lorca, 1921)

\subsection{ANima OLEA EN ANTONio MaChado}

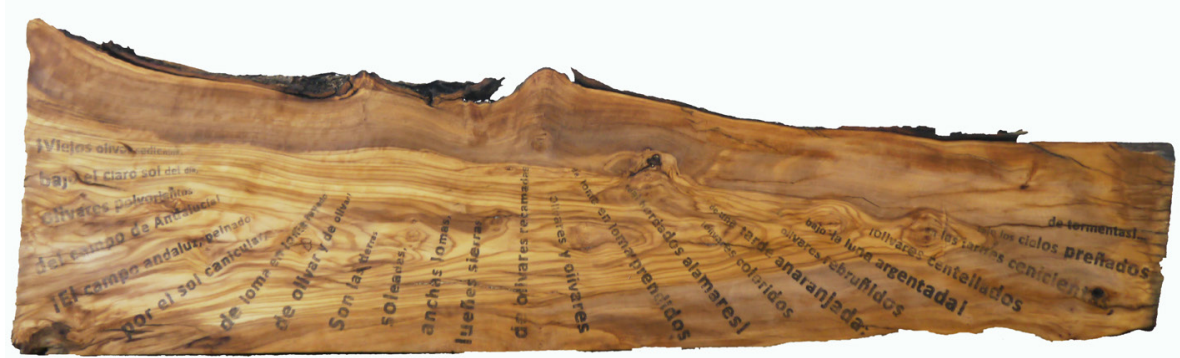

Fig. 12 Anima olea (Antonio Machado), 2019.

Transferencia sobre madera de olivo viejo. 20 × 84 × $3 \mathrm{~cm}$

El campo andaluz, peinado

por el sol canicular,

de loma en loma rayado

de olivar y de olivar!

Son las tierras

soleadas,

anchas lomas,

lueñes sierras

de olivares recamadas.

Mil senderos. Con sus machos,

abrumados de capachos,

van gañanes y arrieros.

¡De la venta del camino

a la puerta, soplan vino

trabucaires bandoleros! 
¡Olivares y olivares

de loma en loma prendidos

cual bordados alamares!

¡Olivares coloridos

de una tarde anaranjada;

olivares rebruñidos

bajo la luna argentada!

¡Olivares centellados

en las tardes cenicientas,

bajo los cielos preñados

de tormentas!...

(Antonio Machado, 1907)

2.3.D. ANIMA OLEA EN MACHADO II

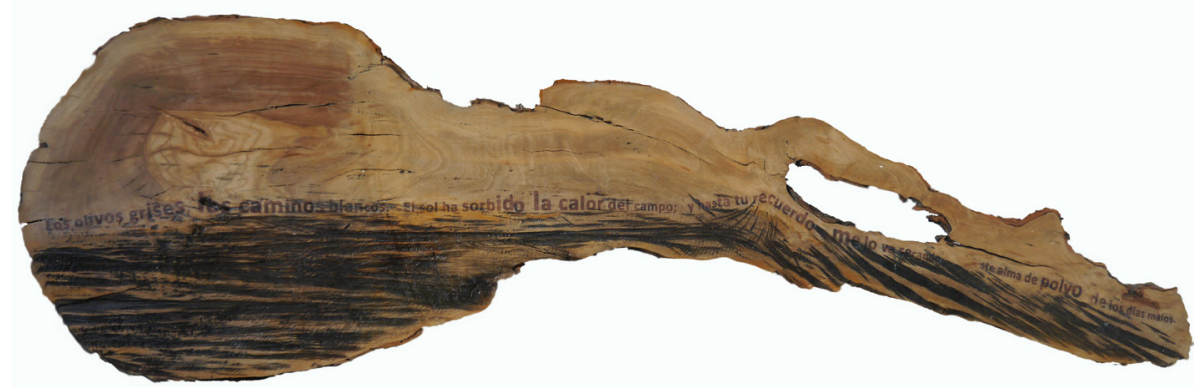

Fig. 13 Anima olea (Antonio Machado), 2019.

Transferencia sobre madera de olivo viejo. $20 \times 84 \times 3 \mathrm{~cm}$

Los olivos grises,

los caminos blancos.

El sol ha sorbido

la calor del campo;

$y$ hasta tu recuerdo

me lo va secando

este alma de polvo

de los días malos.

(Antonio Machado) 


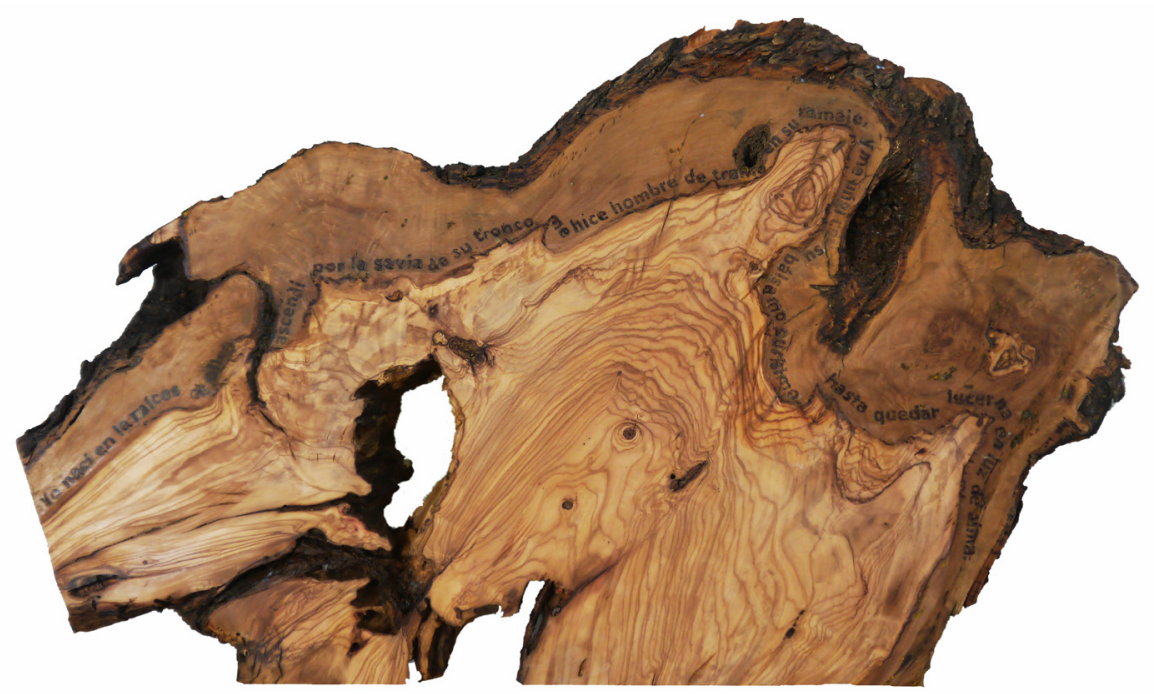

Fig. 14 Anima olea (José María Lopera), 2019.

Transferencia sobre madera de olivo viejo. 36 × 52 × $4 \mathrm{~cm}$

Yo naci en las raíces del olivo,

ascendi por la savia de su tronco,

me hice hombre de trama en su ramaje,

y me ungi con su bálsamo purísimo

hasta quedar lucerna en luz de alma.

(José María Lopera)

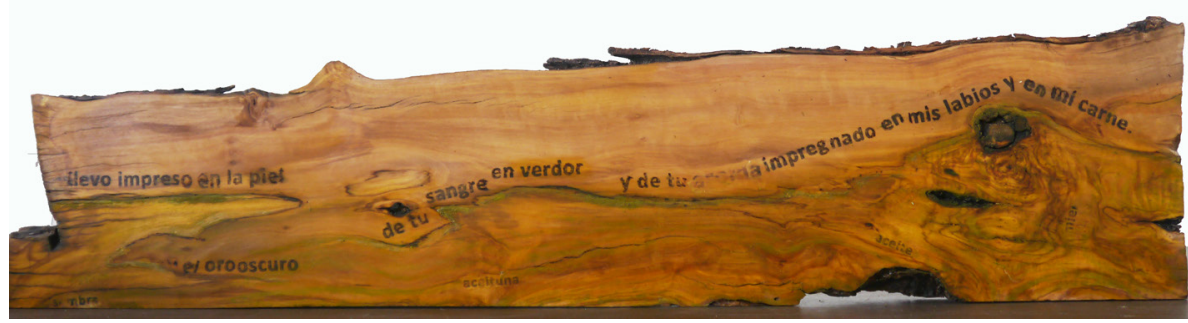

Fig. 15 Anima olea (José María Lopera), 2019.

Transferencia sobre madera de olivo viejo. $22 \times 71 \times 3 \mathrm{~cm}$ 
En definitiva, las distintas piezas de la serie Anima olea nos invitan a redescubrir y materializar la poesía del olivo a través de su propia madera, subrayando metáforas, personificaciones y otras creaciones literarias inspiradas en el eterno paisaje del olivar.

\subsection{MUtATiO}

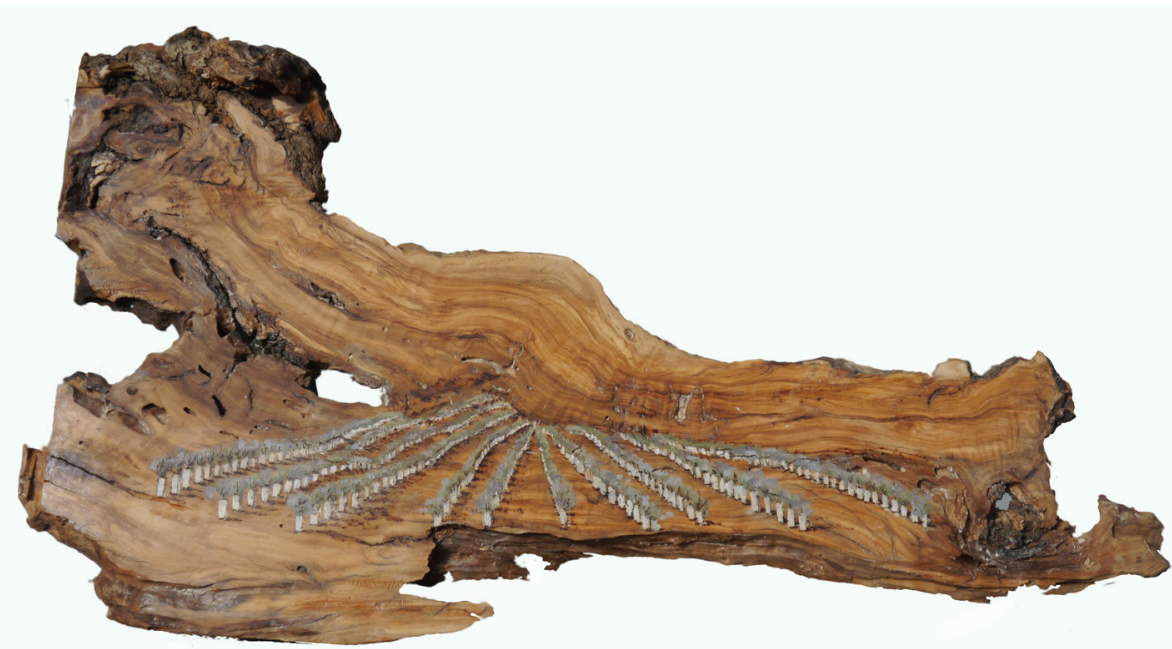

Fig. 16 Mutatio, 2019.

Acrílico sobre madera de olivo viejo. $25,5 \times 101 \times 7,5 \mathrm{~cm}$

Un mundo lineal y dominado, de orden y repetición, retícula de ojos verdes con sabor amargo sobre el viejo olivar que se desmorona ante los requisitos del mercado. Se utiliza como soporte madera obtenida de olivo viejo seca, lijada y preparada. Sobre la madera de los troncos que han sido arrancados para sembrar el olivar en espaldera se representan estos conformando un paisaje severo y homogéneo. La sombra de cada olivo ha sido dibujada con fuego sobre la madera.

\subsection{KINTSUGI}

El proceso de industrialización acelerada que ha tenido lugar en la segunda mitad del siglo XX, que incluso ha derivado en el nacimiento de una nueva era geológica (el Antropoceno), ha estado acompañado de grandes posibilidades de desarrollo pero también está detrás de múltiples amenazas para el futuro del sector, amenzas de las que no es ajena el olivar (Beaufoy, 2001, Gómez, 2009 y Guzmán, 2011; Foraster, 2016). La presión económica está llevando a la sustitución del cultivo de olivar tradicional por el cultivo en espaldera que sustituye el uso de la mano de obra por maquinaria e insumos químicos y agua. Como resultado 


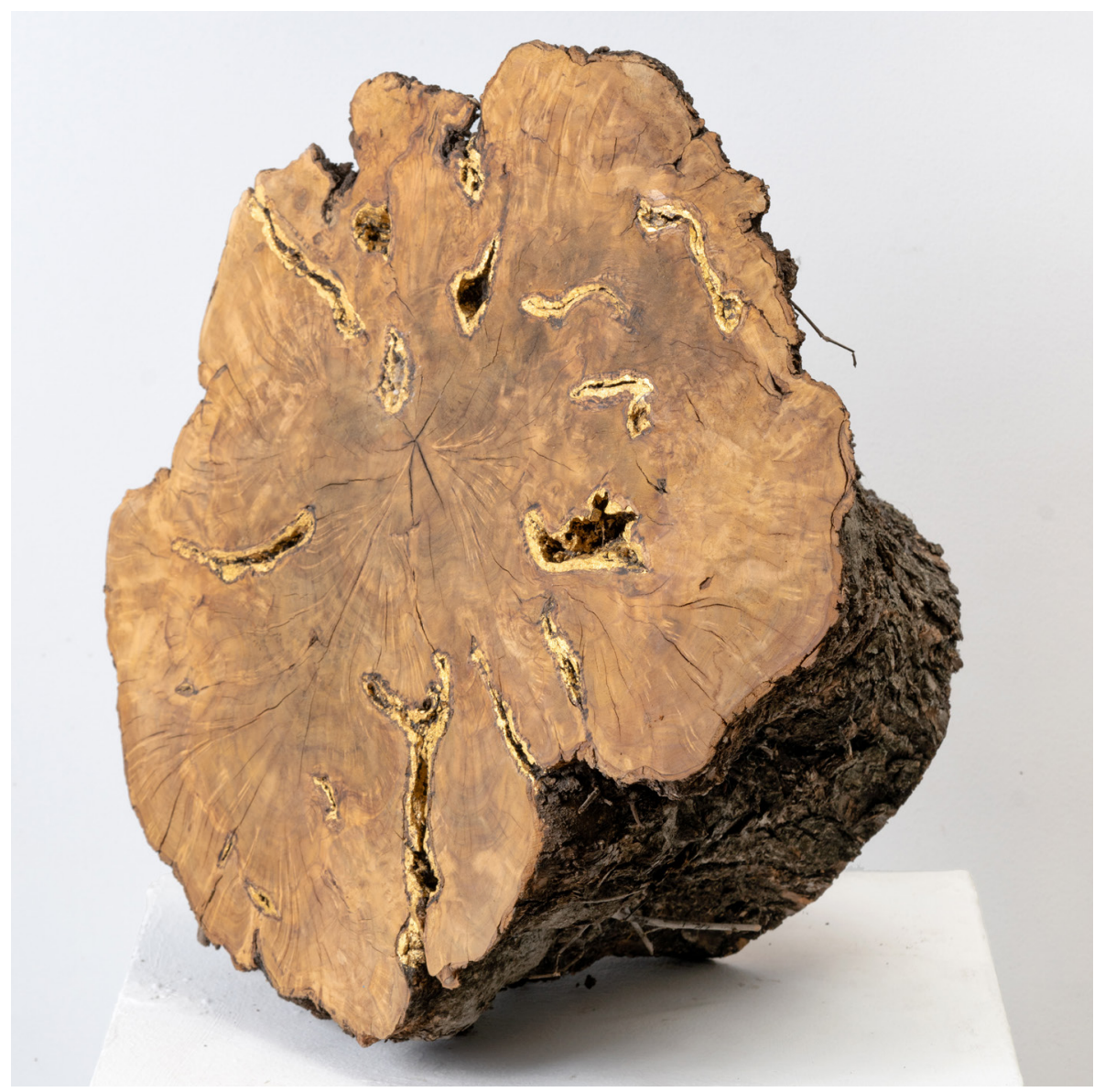

Fig. 17 Kintsugi, 2019.

Pan de oro sobre tronco de olivo viejo. $31 \times 47,5 \times 40 \mathrm{~cm}$

de este proceso, los olivares centenarios se están viendo sustituidos por nuevos garrotes alineados a corta distancia que permiten la mecanización del cultivo y la sustitución de la imagen del olivar por líneas geométricas y definidas..

El kintsugi es la práctica japonesa de reparar fracturas en la cerámica con barniz y oro. Esta técnica responde al reconocimiento de las roturas como parte de la historia de los objetos que los hacen únicos y definen su identidad. De esta forma, la reparación transforma estéticamente la pieza reparada, dándole así un nuevo valor. El oro en las cicatrices de la madera de olivo, pone de manifiesto el valor identitario del olivo en nuestra cultura.

Sobre la madera se ha transferido fragmentos del texto de Antonio Muño Rojas que describía con tanto acierto algunos los procesos de cambio en este sentido: 


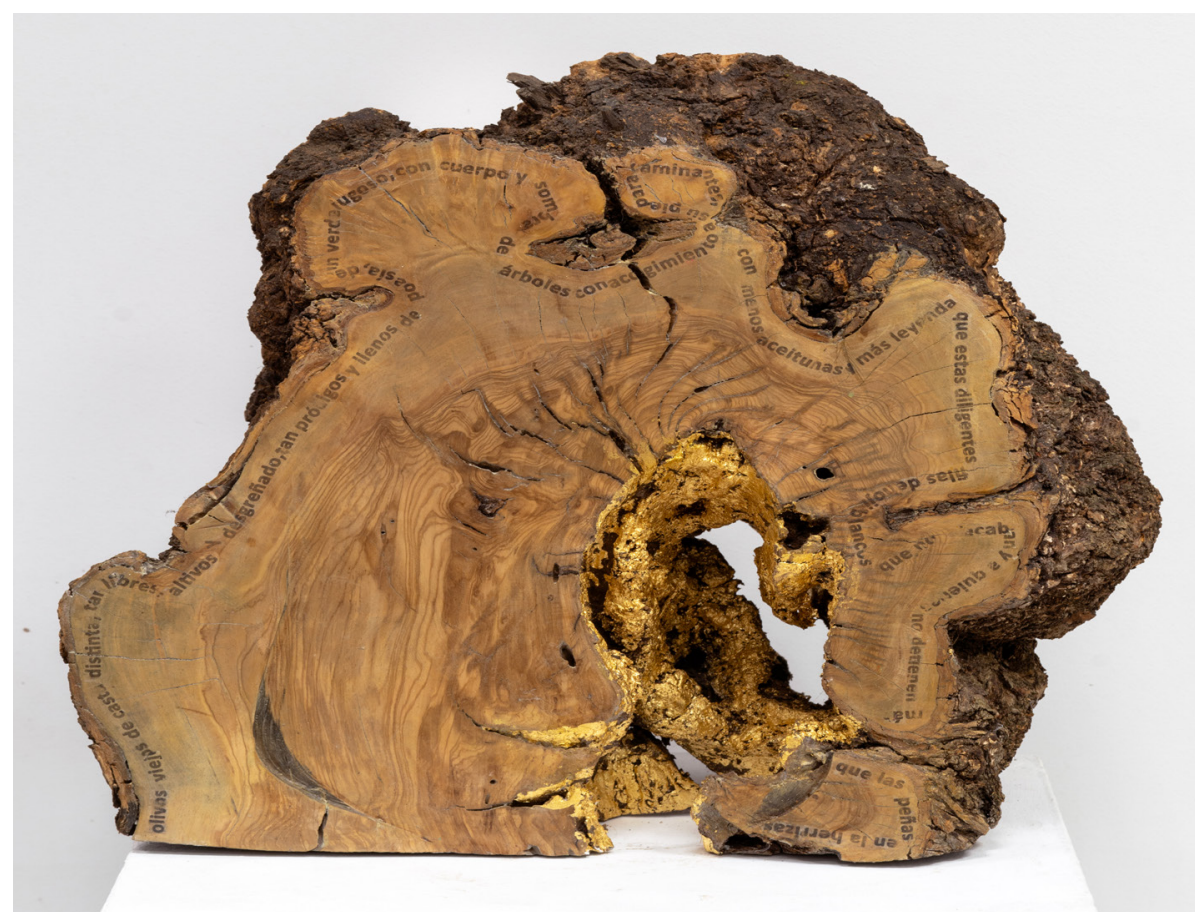

Fig. 18 Kintsugi, 2019.

Pan de oro sobre tronco de olivo viejo. 46 × $45 \times 27,5 \mathrm{~cm}$

olivos viejos de casta distinta, lechines, manzanillos, injertos algunos en acebuches por las cercanias de montes y cañadas, rebajados otros, hijos de mala madre, sin orden en su conjunto, tan libres, altivos y desgreñado, tan pródigos y llenos de poesía, bailadores eternos en el campo, de un verde jugoso, con cuerpo y sombra de árboles con acogimiento a su pie para caminantes, con menos aceitunas y más leyenda que estas diligentes filas de hojiblancos que no se acaban y a quienes no detienen más que las peñas en la herrizas y los limos de los ríos donde llegan a correr (Muñoz Rojas, 1953 (2006):167-168)

\subsection{LAS BUENAS MALAS HIERBAS/VIRIDITAS BONIS}

Ante la ostensible pérdida de biodiversidad en unos olivares que -por la adición de productos químicos- se quedan desnudos, sin su variopinta cubierta vegetal y dejan de ser sustanciales biotopos de una diversificada flora y fauna silvestre (Muńoz-Cobo et al., 2001; Foraster, 2016), y el constatado aumento de los procesos erosivos en un contexto mediterráneo, Vididitas bonis destaca la importancia y la belleza de la flora que acompaña al olivar andaluz en su diversidad y sus funciones. 


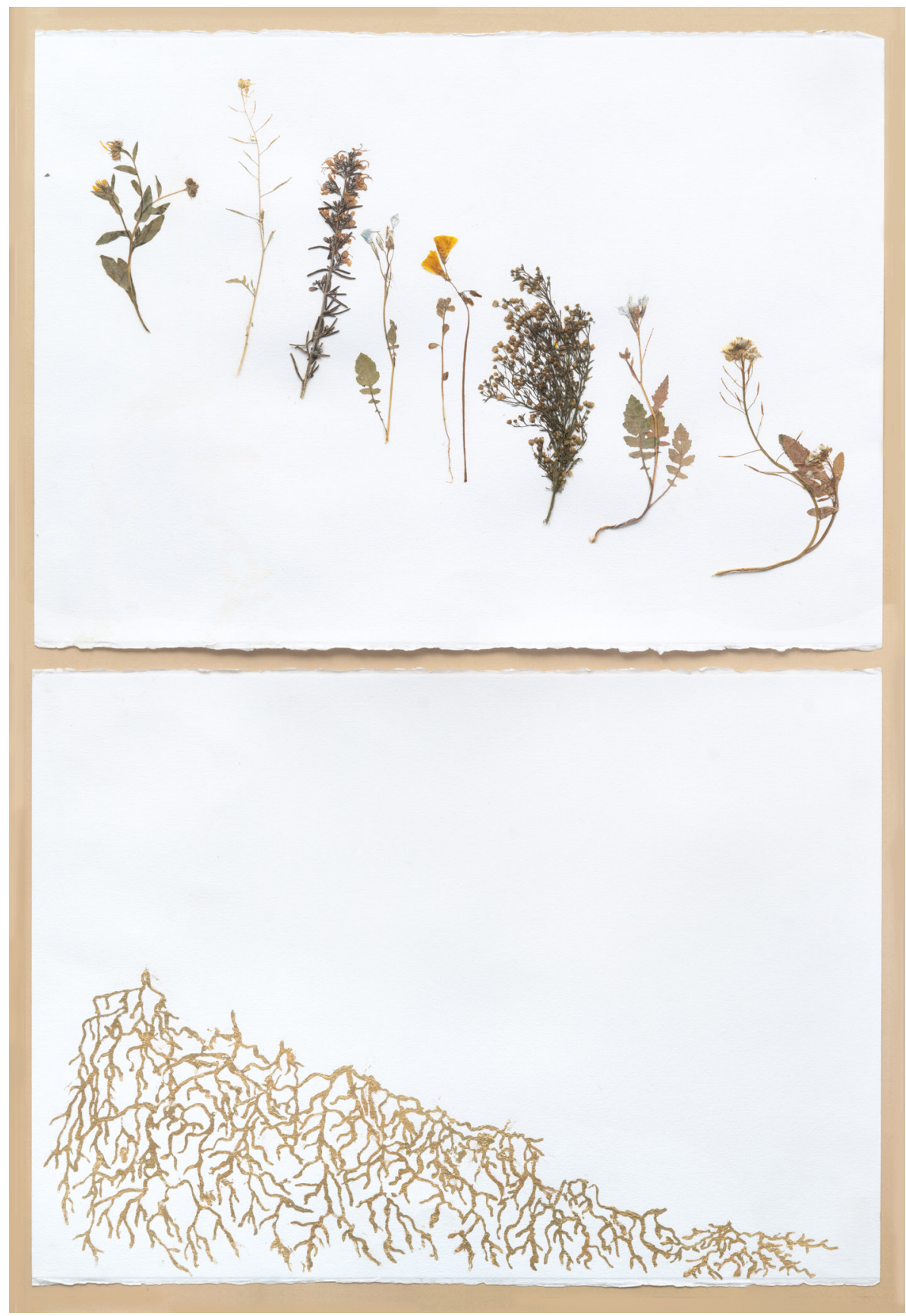

Fig. 19 Las malas hierbas / Viriditas bonis, 2019.

Flores secas y pan de oro. 2 piezas de $50 \times 70 \mathrm{~cm}$ c/u. 
El proceso de creación parte del paseo por el olivar del aljarafe. Se han recolectado y secado algunas de las hierbas que conforman la cobertura vegetal del olivar. Las raíces de las plantas se han singularizado simbólicamente como un entramado dorado con el fin de resaltar su valor en la consolidación de terrenos con pendientes evitando su erosión y aumentando la infiltración de agua.

Esta interpretación que pone en valor aquellas plantas que tradicionalmente se asocian al cultivo del olivo y que han sido combatidas como "malas hierbas" nos recuerda que este masivo e intensificado olivar andaluz ha ido pasando de ser sumidero neto de carbono a constituirse en un emisor del mismo y de otros gases de efecto invernadero (Aguilera et al., 2015). El modelo industrializado e impactante del cultivo del olivo actual, la mecanización y la adición no sólo de agua sino de otros insumos externos de origen inorgánico como respuesta a las necesidades de un mercado expansivo y de periodicidad inflexible, ha ido conduciendo a cuestionables manejos y gestiones de aquellos bellos e identitarios paisajes. Viriditas bonis, destaca no sólo la belleza de la cobertura vegetal sino su valor ecológico en nuestro territorio cargado de pendientes y con un clima semiárido.

\section{Conclusiones}

Anima olea constituye el resultado de una investigación abierta sobre los paisajes del olivar partiendo del método de lectura transdiciplinar del paisaje propuesto por el profesor Juan F. Ojeda-Rivera. A través de las distintas piezas creadas pueden apreciarse las fases del proceso de investigación desarrollado:

- Una primera exploración disciplinar, que desde el arte se desarrolla mediante los estudios y bocetos realizados in situ.

- El diálogo interdisciplinar donde se comparten los resultados con los estudios realizados por las distintas disciplinas implicadas (en este proyecto la historia y la geografía). En esta fase se seleccionan las aportaciones y se organizan el conocimiento y las experiencias aportadas por estas disciplinas para facilitar el avance en el conocimiento.

- Una tercera fase hasta la presentación de distintos arquetipos del paisaje olivarero actual como fruto de un diálogo transdiciplinar sobre las mismas (Diversitas olea). Las imágenes creadas en estas piezas destacan las distintas funcionalidades y adaptaciones históricas y geográficas de los manejos del acebuche y el olivar para recordarnos la complejidad del árbol y de las sabias y elaboradas respuestas que culturalmente se han dado a las necesidades en este territorio mediterráneo.

El conjunto de obras creadas representa la utilización de distintos recursos artísticos para incidir en el carácter único y excepcional del olivar y, por tanto, de su condición de patrimonio de la humanidad, que no sólo se sustenta en su 
formidable dimensión (se trata de la mayor concentración arbórea del continente europeo), sino también en la relevancia milenaria que ha tenido para las culturas de los distintos pobladores mediterráneos. En definitiva, los resultados de la alianza de las distintas disciplinas implicadas en los trabajos presentados facilitan la transferencia de los resultados, que ya habían sido publicados en revistas y libros, a un público no especializado que a través de las imágenes creadas pueden reconocer la diversidad de los paisajes que tienen el olivo como fundamento.

Por otra parte, la serie de obras que Anima olea dedica a la poesía constituye un instrumento útil para recordarnos que la importancia del olivo no solo deviene del hecho de que sus frutos formen parte esencial de la dieta mediterránea y de la fabricación de medicamentos. La literatura, entre otros modos de expresión, se ha hecho eco del vínculo emocional de nuestra cultura con el olivo. Identificando algunos de los versos más significativos en esta alianza a la belleza de la madera del olivo, sus cicatrices y heridas, esta serie nos anima a detenernos y reconocernos en el olivo, reforzando este vínculo en la experiencia de la lectura de los poemas que se dibujan siguiendo el ritmo de los paisajes que crean las vetas propias de la madera.

El olivo, sus productos y sus paisajes constituyen hoy un ejemplo de repositorio de conocimientos agroecológicos, artesano-industriales y estéticosimbólicos de la región mediterránea y de su identidad. Pero, aunque el olivar actual contiene saberes milenarios y ha estado presente en la vida cotidiana y en los grandes eventos de un territorio, debemos ser conscientes de que el modelo industrializado e impactante actual puede quebrar su sostenibilidad futura. La serie vididitas bonis reivindica la importante función de las malas hierbas que formaban parte del olivar tradicional y cuya eliminación sistemática facilita la erosión, la pérdida de suelo y la biodiversidad asociada al olivo.

El reconocimiento y admiración de este proyecto por los paisajes multifuncionales y variopintos del olivar tradicional y a la cultura que ha generado como signos de desarrollo cualitativo es una forma de respeto a la inteligencia mediterránea compartida y acumulada milenariamente.

\section{Bibliografía}

Beaufoy, G. (2001). EU policies for olive farming. Unsustainable on all counts, Brussels: BirdLife International, <http://www.wwf.org.uk/filelibrary/pdf/ oliveoil.pdf> [27 de noviembre de 2016]

Berque, A. (2009). El pensamiento paisajero. Madrid: Biblioteca Nueva.

Besse, Jean Marc. (2000). Voir la terre. Six essais sur le paisaje et la géographie. París: Actes Sud.

Bilbao, D.; Ojeda, J.F.; Villa, J. y Villa, A.A, (2015). Doñana, el paisaje relatado. Itinerarios de acercamiento a Doñana desde sus relatos. Granada: Entorno Gráfico Ediciones S.L. Cuadernos de Paisaje 
Caballero Sánchez, J.V. (2009). Consideraciones sobre la naturaleza hermenéutica de la descripción geográfica. Las lecciones del "Tableau de la géographie de la France”. En Feria Toribio, J. M.; García García, A.; Ojeda Rivera, J. F., Territorios, sociedades y políticas, (pp. 27-40). Sevilla: Universidad Pablo de Olavide,.

Foraster, L. (2016). Transición agroecológica del olivar. Estudio de caso. Tesis doctoral inédita. Universidad Internacional de Andalucía.

García Lorca, F. (1921). Poemas del cante jondo, https://federicogarcialorca.net/ obras_lorca/poema_del_cante_jondo.htm

Gómez Calero, J.A. (2009). Olivar sostenible. Prácticas para una producción sostenible de olivar en Andalucía, <www.ias.csic.es/sostenibilidad_olivar/ BPA_2009/BPA_VF_Jan2010.pdf.>. [18 de octubre de 2016]

González Bernáldez, F. (1992). La frutalización del paisaje mediterráneo. En: VV.AA. Paisaje Mediterráneo, Milán, Electa, pp. 136-142

Guzmán, J.R. (2005). Territorio y medio ambiente en el olivar andaluz. Sevilla: Consejería de Agricultura y Pesca.

Guzmán, G. (2011). El olivar ecológico, Madrid: Mundi Prensa.

Infante-Amate, J. y González de Molina, M. (2013). The Socio-Ecological Transition on a crop scale. The case of olive orchards in S. Spain (1750-2000). Human Ecology, 41 (6), 961-969.

Infante-Amate, J. (2014). ¿Quién levantó los olivos? Historia de la especialización olivarera en el sur de España (ss. XVIII-XX), Madrid: Ministerio de Agricultura, Alimentación y Medio Ambiente.

Junta de Andalucía. Consejería De Agricultura y Pesca (2002). El olivar andaluz, Sevilla.

López Gómez, C. (2011). Valores paisajisticos de las Sierras del Estrecho (Cádiz). Una perspectiva hermenéutica. Tesis doctoral dirigida por Ma Fernanda Pita López y Juan Vicente Caballero Sánchez. Sevilla: Universidad de Sevilla.

Machado, A. (1907). Soledades, Galerías y otros Poemas; (1924). Nuevas canciones; (1907-17). Campos de castilla. En Alvar, M. (ed.) (1975), Poesías completas. (11ª 1985 edición). Madrid: Espasa Calpe.

Martínez de Pisón, E. (2012). Imagen del paisaje. La generación del 98 y Ortega y Gasset. Madrid: Fórcola,.

Muñoz-Cobo, J.M., Klemming, J. M., Romero, C., \& Torres, M. J. R. (2001). Análisis cualitativo y cuantitativo de las comunidades de aves en cuatro tipos de olivares en Jaén (I) comunidades primaverales. Boletín de sanidad vegetal. Plagas, 27 (2), 259-274 
Muñoz Rojas, J. A. (2006). Textos poéticos (1929-2005). Madrid: Cátedra, Letras Hispánicas.

Ojeda Rivera, J. F. (2013). Lectura transdisciplinar de paisajes cotidianos, hacia una valoración patrimonial. Método de aproximación. [En línea] Revista invi, (28), 78, 25-75. <www.revistainvi.uchile.cl< y <www.scielo.cl>

Ojeda Rivera, J.F. (2015). Doñana. Anatomía de la Vera. Madrid, MAGRAMA.

Ojeda-Rivera, J.F., Andreu-Lara, C., Infante-Amate, J. (2018). Razones y recelos de un reconocimiento patrimonial: los paisajes del olivar andaluz. Boletín de la Asociación de Geógrafos Españoles, 1-29 DOI: http://dx.doi.org/10.21138/ bage. 2471

https://www.age-geografia.es/ojs/index.php/bage/article/view/2471

Santano, J.A.(2008). El olivo en la poesía, El olivar de la luna. Creación crítica y literaria (blog en linea) [consulta 14 de febrero de 2018] disponible en: https:// elolivardelaluna.wordpress.com/2008/02/09/el-olivo-en-la-poesia-3/

Zambrana, J.F. (1987). Crisis y modernización del olivar. Madrid: Ministerio de Agricultura, Pesca y Alimentación. 